\title{
A data assimilative perspective of oceanic mesoscale eddy evolution during VOCALS-REx
}

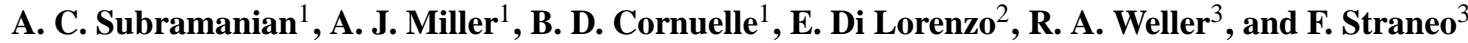 \\ ${ }^{1}$ Scripps Institution of Oceanography, University of California, San Diego, La Jolla, California, USA \\ ${ }^{2}$ Georgia Institute of Technology, Altlanta, Georgia, USA \\ ${ }^{3}$ Woods Hole Oceanographic Institution, MIT, 86 Water Street, MA, USA
}

Correspondence to: A. C. Subramanian (acsubram@ucsd.edu)

Received: 25 July 2012 - Published in Atmos. Chem. Phys. Discuss.: 20 August 2012

Revised: 22 January 2013 - Accepted: 4 February 2013 - Published: 25 March 2013

\begin{abstract}
Oceanic observations collected during the VOCALS-REx cruise time period, 1-30 November 2008, are assimilated into a regional ocean model (ROMS) using 4DVAR and then analyzed for their dynamics. Nonlinearities in the system prevent a complete 30-day fit, so two 15-day fits for 1-15 November and 16-30 November are executed using the available observations of hydrographic temperature and salinity, along with satellite fields of SST and sealevel height anomaly. The fits converge and reduce the cost function significantly, and the results indicated that ROMS is able to successfully reproduce both large-scale and smallerscale features of the flows observed during the VOCALSREx cruise. Particular attention is focused on an intensively studied eddy at $76^{\circ} \mathrm{W}, 19^{\circ} \mathrm{S}$. The ROMS fits capture this eddy as an isolated rotating 3-D vortex with a strong subsurface signature in velocity, temperature and anomalously low salinity. The eddy has an average temperature anomaly of approximately $-0.5^{\circ} \mathrm{C}$ over a depth range from $50-600 \mathrm{~m}$ and features a cold anomaly of approximately $-1{ }^{\circ} \mathrm{C}$ near $150 \mathrm{~m}$ depth. The eddy moves northwestward and elongates during the second 15-day fit. It exhibits a strong signature in the Okubo-Weiss parameter, which indicates significant nonlinearity in its evolution. The heat balance for the period of the cruise from the ocean state estimate reveals that the horizontal advection and the vertical mixing processes are the dominant terms that balance the temperature tendency of the upper layer of the ocean locally in time and space. Areal averages around the eddies, for a 15-day period during the cruise, suggest that vertical mixing processes generally balance the surface heating. Although, this indicates only a small role for lateral advective processes in this region during this pe-
\end{abstract}

riod, this quasi-instantaneous heat budget analysis cannot be extended to interpret the seasonal or long-term upper ocean heat budget in this region.

\section{Introduction}

The climate of the Southeast Pacific (SEP) involves important feedbacks between atmospheric circulation, sea-surface temperature (SST), clouds, ocean heat transport, aerosols in a region with a complex coastal orography and bathymetry (Mechoso et al., 1995; Ma et al., 1996; Xie, 2004). The Andes mountains channel strong southerly winds along the coast generating vigorous coastal upwelling (Garreaud and Muñoz, 2005; Amador et al., 2006). The resulting equatorward Peru-Humboldt Current is baroclinically unstable and develops nonlinear mesoscale eddies and westward propagating Rossby waves that re-distribute the cold water more than a thousand kilometers offshore (Penven et al., 2005; Colas et al., 2011). The cool water helps maintain the low-level clouds, whose shade helps keep the waters cool (Klein and Hartmann, 1993; Zheng et al., 2011). The cloud formation depends on aerosols, which are produced both by ocean biology and by human industrial activities along the coast (Hind et al., 2011; Yang et al., 2011, 2009).

The VOCALS (VAMOS Ocean Cloud Atmosphere Land Study) REx (Regional Experiment) campaign was designed to address the fundamental dynamics that control the largescale ocean-atmosphere system in the SEP (Wood et al., 2011; Zheng et al., 2011). Teams of national and international collaborators measured, analyzed, and modeled the 


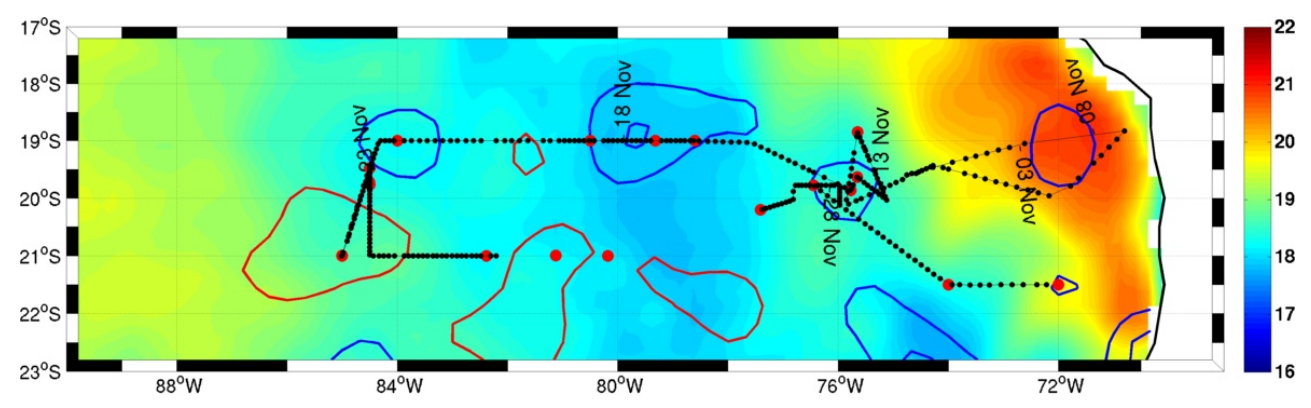

Fig. 1. SST $\left({ }^{\circ} \mathrm{C}\right)$ from AVHRR for 18 November 2008 (color contours) and $\pm 5 \mathrm{~cm}$ Sea Level anomaly contours (line contours) from AVISO during VOCALS cruise period. The cyclonic eddies are marked as blue contours and the anticyclonic ones as red. The NOAA ship Ron Brown cruise track from 1 to 30 November 2008 is shown as points where the 438 UCTD (black dots) and CTD (large red dots) casts were taken.

large-scale atmospheric subsidence, broad regions of stratocumulus clouds, cool sea-surface temperature, upwelling ocean boundary currents and energetic mesoscale ocean eddies, which all interact in complicated ways to affect local, basin-scale and global-scale climate variability (Mechoso et al., 1995; Wood et al., 2011).

The mesoscale eddies of the ocean circulation observed during VOCALS-REx make up the component of the system that is the focus of this study. These eddies can affect the distribution of sea-surface temperature (SST) in the eastern tropical Pacific in two major ways. The eddy heat fluxes along with vertical mixing processes in the region drive SST changes that affect the atmospheric boundary layer by altering its stability and consequent heat, momentum and moisture fluxes at the air-sea interface (Large and Danabasoglu, 2006; Capet et al., 2008; de Szoeke et al., 2010; Zheng et al., 2010). The eddies also affect nutrient transport into and within the euphotic zone, which controls ocean biology. Chelton et al. (2011b) show that on timescales greater than 23 weeks, eddy-induced horizontal advection of chlorophyll is the dominant mechanism that determines the chlorophyll variability in eddy active regions such as the SEP. Eddies consequently affect air-sea fluxes of volatile organic compounds, such as DMS, that convert into cloud condensation nuclei and radiative scattering aerosols in the atmosphere (Clarke et al., 1998; Yang et al., 2009, 2011).

In order to better understand the time-dependent evolution of the eddy field that was observed during VOCALS-REx, we use an ocean data assimilation technique to produce a time-dependent reconstruction of the flow fields around the cruise tracks. The resulting "fits" give a more complete depiction of the key ocean eddy components of the system that were studied using observations alone. By constraining the observations with ocean dynamics, for example, we can follow a key subsurface eddy, and analyze its water mass properties and its dynamics and isolate the upper-ocean heat balance terms during the cruises. We can also quantify the relative strength of strain versus vorticity in the flow field of the system and offer a dynamical view about dominant processes that could have influenced the biogeochemical processes during the campaign.

Section 2 describes the data available for the assimilation experiment. Section 3 presents the basics of the model and the assimilation procedure. Section 4 describes the results of fits, and Sect. 5 provides a summary and discussion of results.

\section{Observations during VOCALS-REx}

\subsection{Oceanographic in-situ data}

Subsurface temperature and salinity data were collected by CTD casts along the VOCALS cruise tracks (Wood et al., 2011), which are shown in Fig. 1. At each of the REx major hydrographic stations, marked as large dots, CTD casts to $3500 \mathrm{~m}$ (or near the ocean bottom) were taken over the 38 day experimental time period. Additionally, Underway CTD casts were obtained, typically to depths of $500 \mathrm{~m}$, while underway between these stations. The measurements span the range of 19 to $21.5^{\circ} \mathrm{S}$ and 86 to $72^{\circ} \mathrm{W}$, with a number of stations taken to sample an eddy that was encountered near $20^{\circ} \mathrm{N}, 76^{\circ} \mathrm{W}$. A number of Argo floats also sampled the water column during this time period.

\subsection{Satellite data}

SST data were available from the $10 \mathrm{~km}$ resolution blended satellite product which combines Japan's Advanced Microwave Scanning Radiometer (AMSR-E) instrument, a passive radiance sensor carried aboard NASA's Aqua spacecraft, NOAA's Advanced Very High Resolution Radiometer, NOAA GOES Imager, and NASA's Moderate Resolution Imaging Spectrometer (MODIS) SST data set. Those satellites measure the SST twice a day, but the exact time of the measurement is obscured after the merging process.

Sea Surface Height (SSH) anomaly observations are obtained from the dataset produced by Ssalto/Duacs and distributed by AVISO. Because of errors implicit in estimating 


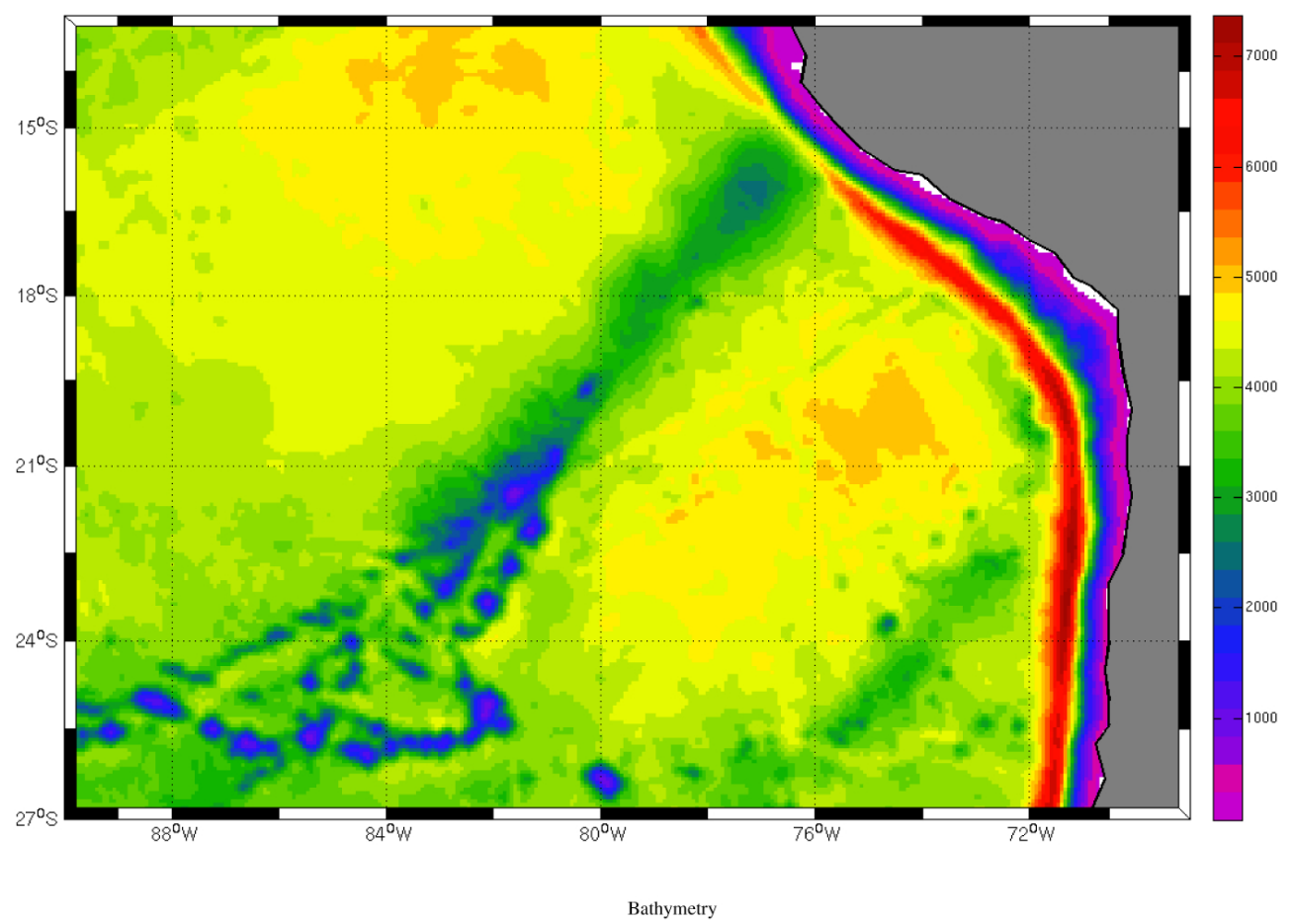

Fig. 2. Horizontal domain used for the ROMS experiments with the model bathymetry (color) plotted in meters depth. The Nazca ridge cuts across the domain diagonally changing depths on either side from 5000 to $2000 \mathrm{~m}$.

the absolute sea level, only the anomalous part of the AVISO $\mathrm{SSH}$ product is used in the assimilation. The along-track SSH anomaly data are added to the mapped temporal mean dynamic topography from the model. Then, the spatial mean of the observation is set to be the same as the model spatial mean.

\subsection{Pre-processing of observations}

If the observations have features whose spatial scales that are smaller than the model can represent, they have no use in a data assimilation experiment. Hence, all observations inside of a model grid cell are averaged if they occur in the same time period. This "super observations" process effectively smooths the highly resolved satellite data to the coarser resolution used in the model.

\subsection{Observational error estimates}

The minimum of the estimated observational error in SST is set to be $0.01{ }^{\circ} \mathrm{C}$. Except for the Argo floats that have their own error estimation, the observational errors for $\mathrm{T}$ are set to be the same as the SST data. The observational errors for S are also one-quarter of the size of the model standard deviation, but the minimum value is set as $0.01 \mathrm{psu}$. The observational error of SLH is set to be $1 \mathrm{~cm}$.

\section{Model and data assimilation procedure}

\subsection{Model setup}

The Regional Ocean Modeling System (ROMS) is a stateof-the-art, free-surface, hydrostatic primitive equation ocean circulation model being used for applications from coastal to basin to global scales by a large global community (Moore et al., 2010; Haidvogel et al., 2008; Shchepetkin and McWilliams, 2005). Shchepetkin and McWilliams (2005) describe the ROMS computational algorithms in detail. This includes the description of the high-precision time-stepping algorithm to allow exact conservation and constancy preservation for tracers, while improving the accuracy and increasing the numerical stability for coastal applications.

This model was configured in a domain to include all the cruise tracks from VOCALS-REx, with additional room outside the intensively sampled region to avoid strong influences of the boundary conditions during the fits. The model domain covers 13 to $27^{\circ} \mathrm{S}$ and 67 to $90^{\circ} \mathrm{W}$ with an approximately $7 \mathrm{~km}$ grid interval, and corresponding smoothed topography (Fig. 2). The grid has 32 terrain-following vertical levels that are concentrated more at the surface and ocean bottom. The vertical mixing in the model was parameterized using the K-profile parameterization (KPP) (Large et al., 1994). Lateral boundary conditions are taken from a ROMS simulation for a domain extending southward from 2 to $43^{\circ} \mathrm{S}$ and westward from 67 to $92^{\circ} \mathrm{W}$. The outer domain grid has an average 


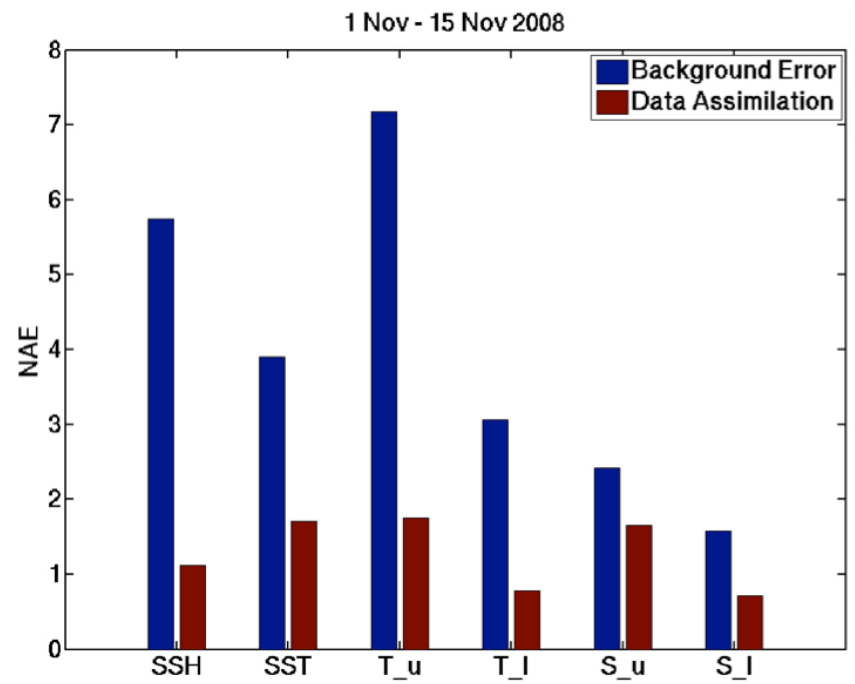

(a) 1-15 November

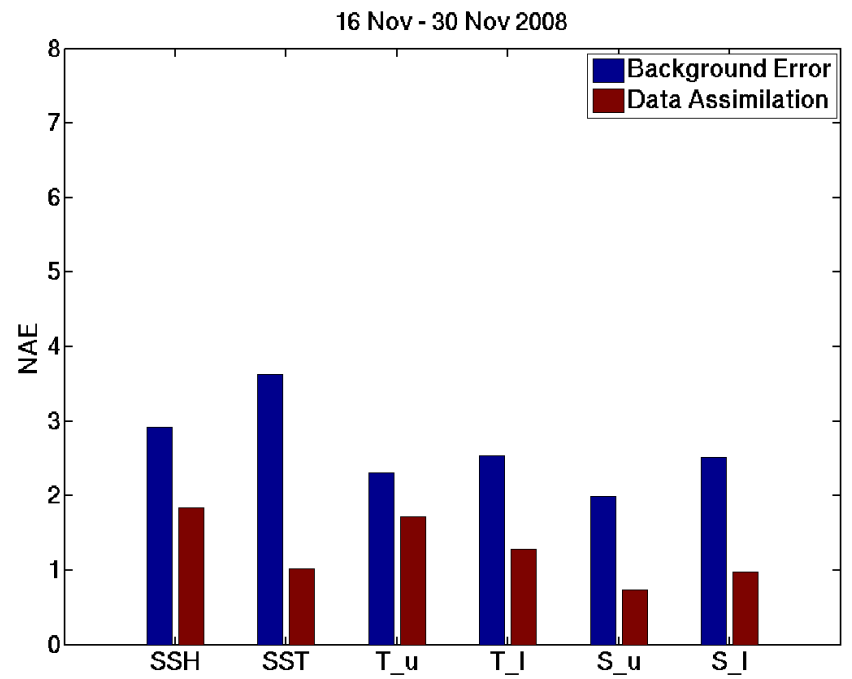

(b) 16-30 November

Fig. 3. Normalized mean absolute error changes for the two 15 day assimilation fits. (a) For the first 15 day fit for 1-15 November 2008. (b) For the second 15 day fit for 16-30 November 2008 for sea surface height ( $\mathrm{SSH}$ ), sea surface temperature (SST), temperature in upper $100 \mathrm{~m}\left(T_{\mathrm{u}}\right)$, temperature below $100 \mathrm{~m}\left(T_{1}\right)$, salinity in upper $100 \mathrm{~m}\left(S_{\mathrm{u}}\right)$ and salinity below $100 \mathrm{~m}\left(S_{1}\right)$.

horizontal resolution of $20 \mathrm{~km}$ with 30 levels in the vertical. The model was first spun up for $56 \mathrm{yr}$ with monthly-mean surface forcing from the National Center for Environmental Prediction/National Center for Atmospheric Research reanalysis (NCEP/NCAR; Kalnay et al., 1996) and initial and boundary conditions from a high-resolution MOM3-based Ocean General Circulation Model (OGCM) code optimized for the Earth Simulator (OFES; Masumoto et al., 2004).
Nov 2008

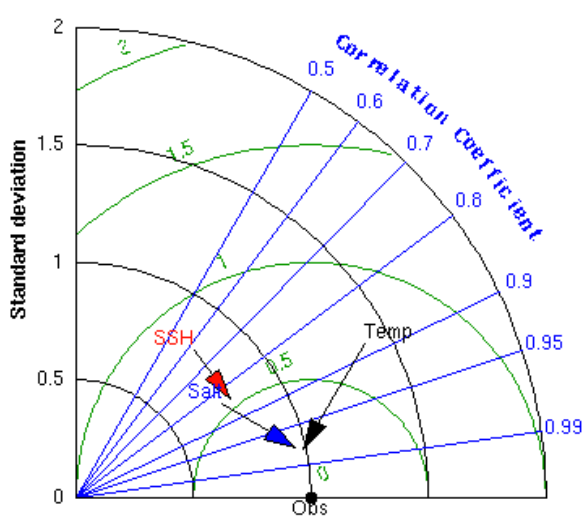

(a) 1-15 November

Nov 2008

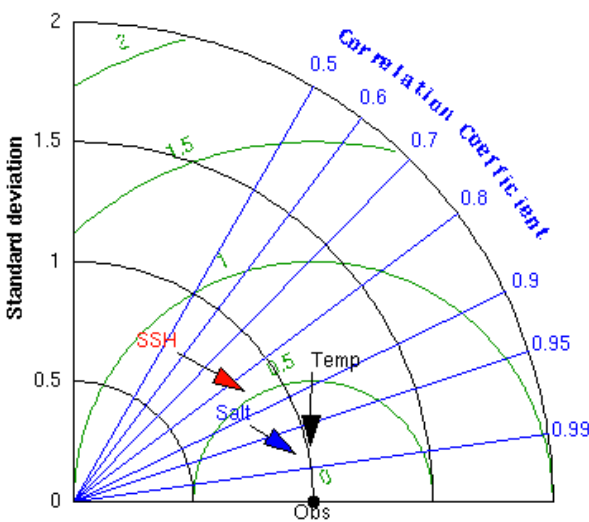

(b) 16-30 November

Fig. 4. Taylor Diagram for the two 15 day assimilation fits. (a) For the first 15 day fit for 1-15 November 2008. (b) For the second 15 day fit for 16-30 November 2008 for salinity (blue arrow), SSH (red arrow) and temperature (black arrow).

Surface boundary conditions for the inner domain for the assimilation fits were taken from QuikSCAT wind stresses and from ECMWF Reanalysis Interim (ERA-I) air-sea flux data using bulk formulation (Fairall et al., 2003). Initial longterm tests of the model domain without assimilation and forced with regional winds produces a mean Peru-Humbodlt current velocity of about $0.2 \mathrm{~m} \mathrm{~s}^{-1}$ which is about $20 \%$ weaker than estimated maximum velocity of $0.25 \mathrm{~m} \mathrm{~s}^{-1}$ as shown in Strub et al. (1998). The eddy kinetic energy in the climatological run is 20 to $30 \%$ lower than in observations. The ROMS model has also been used previously by Colas et al. (2011) to study the mesoscale dynamics in this region and they show a very good fidelity in the model to reproduce the climatology and the spatial statistics of the flow in this region. 


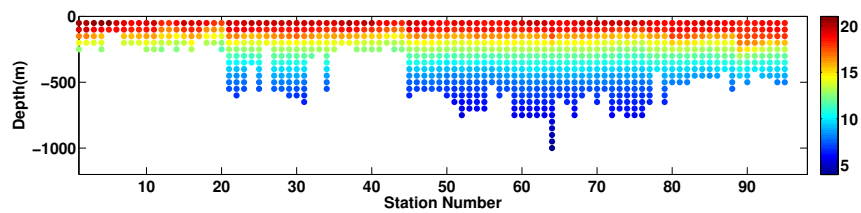

(a) Initial profile temperature in ROMS

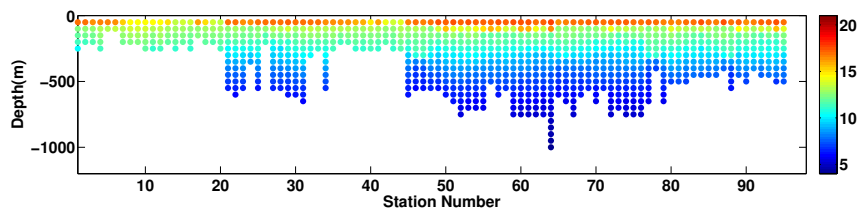

(c) Observed CTD profiles of temperature

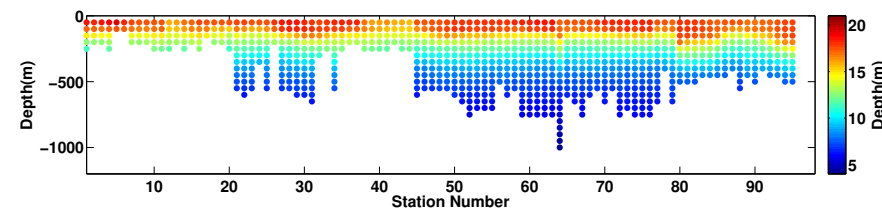

(e) Final profile temperature in ROMS

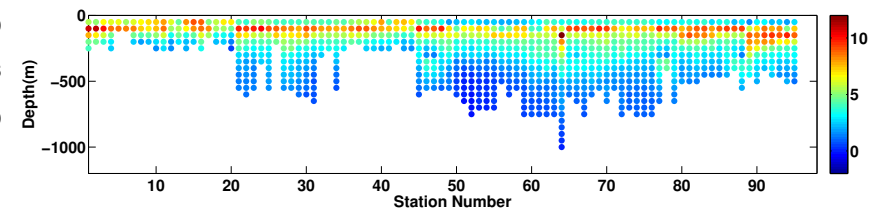

(b) Initial misfit in temperature Profiles in ROMS

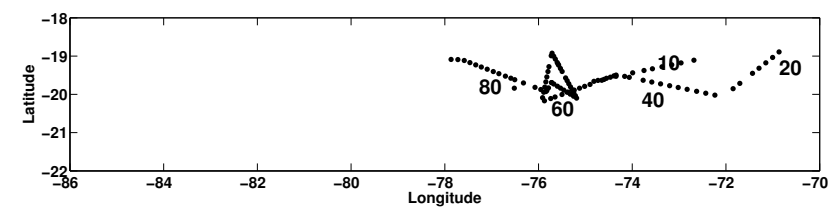

(d) Horizontal positions of Station numbers

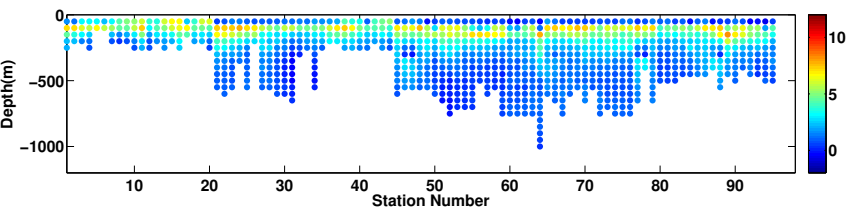

(f) Final misfit in temperature profiles in ROMS

Fig. 5. (a, e) Model temperature profile values (in ${ }^{\circ} \mathrm{C}$ ) before and after assimilation. (c) shows the observed temperature profiles in the same location. The horizontal location of the profiles are shown in (d) which are the same as in the first leg shown in Fig. 1. The initial model misfit before assimilation (d) and the final model misfit after assimilation (f) for the first 15 day fit from 1 to 15 November 2008 is also shown.

\subsection{Assimilation technique}

Data assimilation of the VOCALS-REx cruise time intervals will be achieved using the Incremental Strong-constraint 4-D-variational (IS4DVAR) data assimilation system developed by Moore et al. (2011). The assimilation is performed under the perfect model assumption (strong constraint) as we intend to diagnose physical balances during the VOCALS cruise survey period. The ROMS 4DVAR procedure adjusts the initial condition and surface forcing, within the given error bars, to bring the model fit into a closer correspondence to the observed data, in a least-square sense, over a defined assimilation time window.

This strategy uses the tangent linear and adjoint models (Moore et al., 2010) in an iterative inner loop to deal with the non-linearities of the system. IS4DVAR has been tested by Di Lorenzo et al. (2007) in an idealized 3-D double gyre circulation and in a realistic application for the geometry and bathymetry of the Southern California Bight (SCB), a region characterized by strong mesoscale eddy variability like the SEP. After a first-guess non-linear run of ROMS, several purely linear inner loops are executed to reduce the misfit, as measured by the cost function. Then, a non-linear run is executed again to determine if the misfit is lower than the initial guess. The procedure is then repeated until a satisfactory fit to the observation is achieved.
The goal is to, in a least-squares sense, perturb the circulation to minimize the difference between the observations and model circulation in the new estimated state of the ocean. IS4DVAR produces a new state by correcting the initial conditions. The evolution of the model state is seen to be close to the observations in the assimilation window and to be dynamically consistent at the same time. In order to get the new initial ocean state, $\mathbf{x}(0)=\mathbf{x}_{\mathbf{b}}(0)+\delta \mathbf{x}(0)$, we first define the cost function in terms of $\delta \mathbf{x}(0)$, which is the combination of two terms; changes in the initial model states $\left(J_{\mathrm{b}}\right)$ and residuals from observations $\left(J_{0}\right)$.

It is defined below.

$$
\begin{aligned}
& J(\delta \mathbf{x}(0))= \\
& \underbrace{\frac{1}{2} \sum_{i=1}^{N}\left(\mathbf{H}_{i}\left(\mathbf{x}_{\mathrm{b}}(0)+\delta \mathbf{x}(0)\right)-\boldsymbol{y}_{i}\right)^{T} \mathbf{O}_{i}^{-1}\left(\mathbf{H}_{i}\left(\mathbf{x}_{\mathrm{b}}(0)+\delta \mathbf{x}(0)\right)-\boldsymbol{y}_{i}\right)}_{J_{0}} \\
& +\underbrace{\frac{1}{2} \delta \mathbf{x}(0)^{T} \mathbf{B}^{-1} \delta \mathbf{x}(0)}_{J_{\mathrm{b}}},
\end{aligned}
$$

where $\mathbf{B}$ is the background error covariance matrix, vector $\boldsymbol{y}$ is observations, $\mathbf{H}$ is the tangent linear model which integrates the states linearly and then projects to the observational space, $\mathbf{O}$ is the observational error covariance matrix and $N$ is the number of observation time steps. 


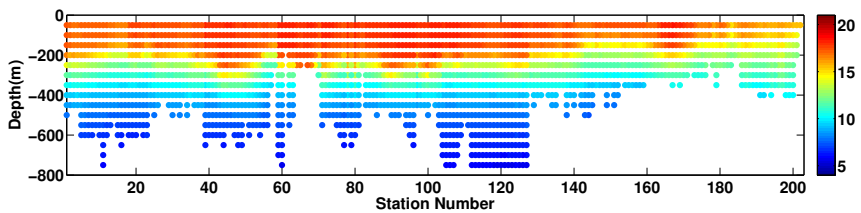

(a) Initial temperature profiles in ROMS

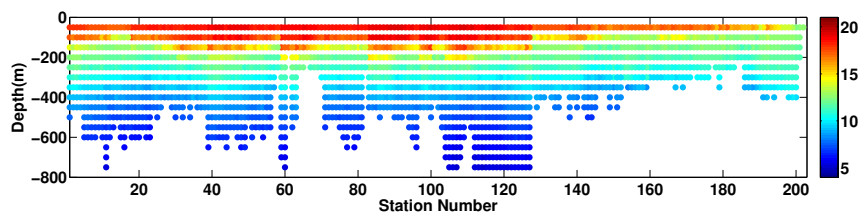

(c) Observed CTD profiles of temperature

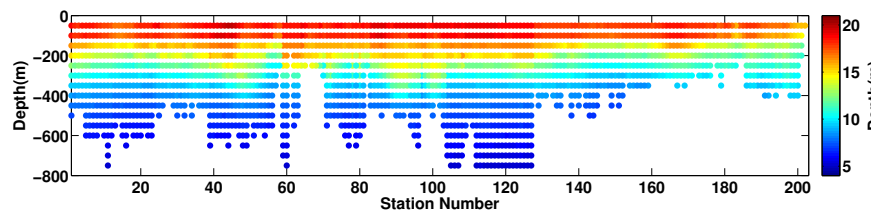

(e) Final temperature profiles in ROMS

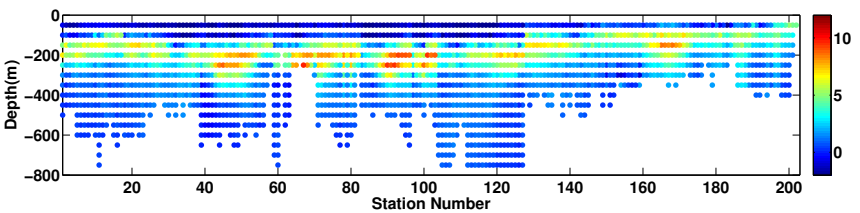

(b) Initial Misfit in temperature Profiles in ROMS

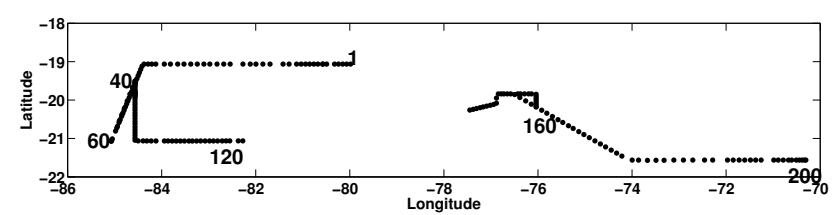

(d) Horizontal positions of Station Numbers

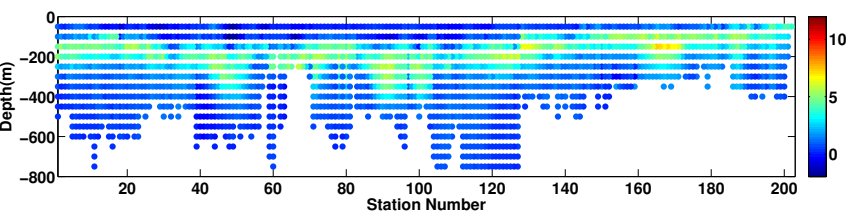

(f) Final Misfit in temperature Profiles in ROMS

Fig. 6. (a, e) Model temperature profile values (in ${ }^{\circ} \mathrm{C}$ ) before and after assimilation. (c) shows the observed temperature profiles in the same location. The horizontal location of the profiles are shown in (d) which are the same as in the second leg shown in Fig. 1. The initial model misfit before assimilation (d) and the final model misfit after assimilation (f) for the second 15 day fit from 16 to 30 November 2008 is shown here.

The solution will minimize the cost function. This means that it will make both the residuals and the changes in the initial states small. The optimal solution for $\delta \mathbf{x}(0)$ satisfies

$\nabla_{\delta \mathbf{x}} J=\mathbf{B}^{-1} \delta \mathbf{x}(0)+\sum_{i=1}^{N} \mathbf{H}_{i}^{T} \mathbf{O}_{i}^{-1}\left(\mathbf{H}_{i}\left(\mathbf{x}_{\mathrm{b}}(0)+\delta \mathbf{x}(0)\right)-\boldsymbol{y}_{i}\right)=0$.

This solution of $\delta \mathbf{x}(0)$ will give us the optimal initial condition that can be used to derive the model state evolution with the least misfit with observations.

Before making the IS4DVAR fits using ROMS, we have to specify the background error covariances for the observations, initial conditions, and surface forcing. Observation errors were assumed to be uncorrelated in space and time, and the main diagonal of the observation error variance matrix were assigned as a combination of model representational error and measurement errors as described in Sect. 2.4.

The model error correlations are only modeled as homogeneous and separable in horizontal and vertical. The decorrelation length scales used to model the background error covariance for the initial state vector were $50 \mathrm{~km}$ in the horizontal and $30 \mathrm{~m}$ in the vertical. Horizontal correlation scales chosen for the background surface forcing field error covariance were $300 \mathrm{~km}$ for the windstress and $100 \mathrm{~km}$ for the heat and freshwater flux. The increments to the surface forcing fields were computed daily, and are interpolated for each intervening model timestep.

The background error covariance matrix for the initial conditions state vector are estimated based on the variance of a prior forward model run with forcing from 2002-2007 with no assimilation. The temporal variance of the ERA-I heat fluxes and QuikSCAT winds are used as the covariance error matrices for the surface forcing fields.

Since the subsurface data was so limited in space, we used an ad hoc procedure to determine the first-guess model state. We collapsed all the observations onto the same time stamp and executed a IS4DVAR fit of a one-day run of the model to that "date" from a random initial state. This is tantamount to using an optimal interpolation of all the data as a first-guess initial condition for the assimilation procedure. The background covariance used for the assimilation procedure was computed as the variance of a $10 \mathrm{yr}$ long model run forced by climatological surface fluxes and boundary conditions.

We first attempted to fit the entire 30 days of the REx cruises, but non-linearities in the system did not admit convergence to a state that resembled the observations. We then broke the REx survey into two 15-day periods, 1-15 November (Fit-1) and 16-30 November (Fit-2), and these converged to realistic representations of the ocean flows. In our case, we 


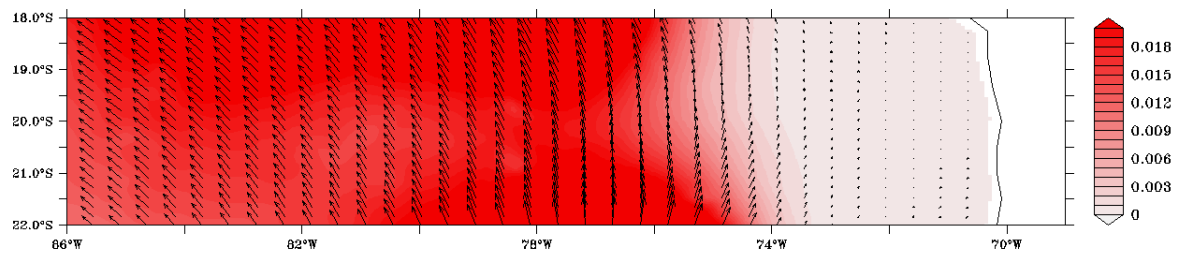

(a) Windstress (Non-assimilated)

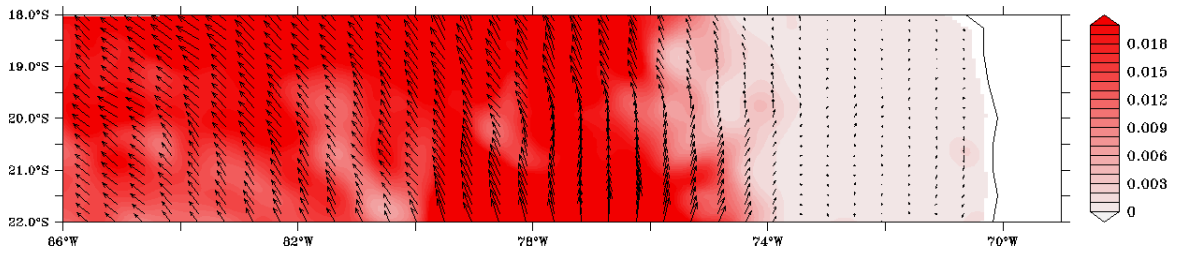

(b) Windstress (Assimilated)

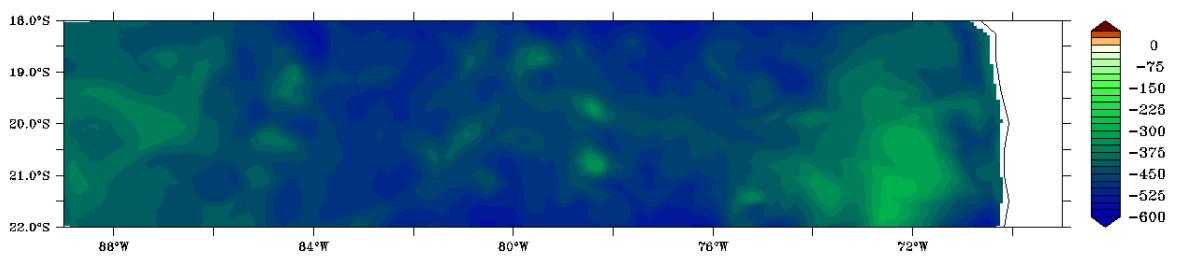

(c) Net Heat Flux (Non-assimilated)

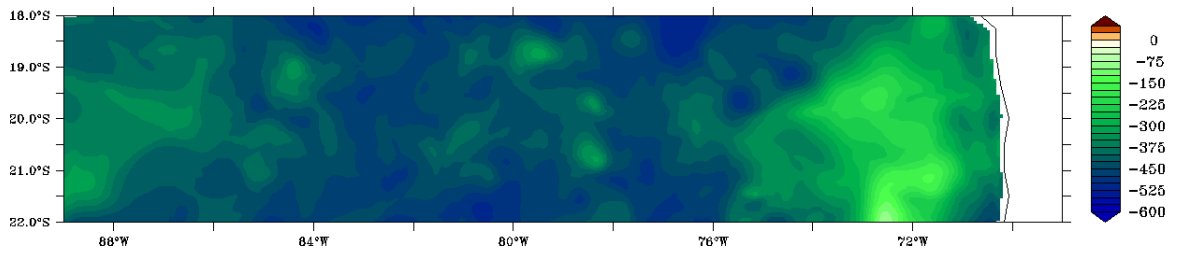

(d) Net Heat Flux (Assimilated)

Fig. 7. Windstress $\left(\mathrm{N} \mathrm{m}^{-2}\right)$ forcing for the ROMS model for the period from 1-15 November 2008 before (a) and after (b) adjustment from assimilation of observations. Net Heat flux $\left(\mathrm{W} \mathrm{m}^{-2}\right)$ forcing for the ROMS model for the period from 1-15 November 2008 before (c) and after (d) adjustment from assimilation of observations.

used fifteen inner loops and three outer (non-linear) loops before arriving at the final state estimate.

\section{Model fitting results}

Figure 3 shows the reduction of the normalized absolute error (NAE) for the total assimilation period. If the NAE is one, it means the misfit between the observation and the interpolated model states is the same as the observational error. In November 2008, the mean NAE became roughly one after the ROMS 4DVAR procedure decreased the normalized misfit by $70 \%$ on average. In general, the reductions of the NAE are greater when the initial errors are larger. The SST has the biggest NAE both before and after the assimilation for the first 15 days and the SSH has the biggest error in the second 15 days. NAEs for other variables are reduced to approximately the observational error level.
Taylor diagrams (Taylor, 2001) offer a visual way to compare the performances of several models with respect to the observations by showing their standard deviation, correlation, and the centered root-mean-square (RMS) difference. Figure 4 shows the changes in normalized statistics for $\mathrm{SSH}$, $T$ and $S$ on the Taylor diagrams for each fit. The arrows indicate the changes in normalized statistics after data assimilation with the start of the arrow indicating the initial model state and the end of the arrowhead at the location of the final model state after assimilation. The data assimilation improved the statistics for all variables in both time periods.

The model fits to subsurface profiles from the CTD casts are shown in Figs. 5 and 6 for the first and second fortnights of November. The fits for both periods show a reduction in the model-data misfits by a large fraction in the upper $200 \mathrm{~m}$ of the profiles where the misfits are the largest. The middle bottom panel in the figures show the horizontal location of 


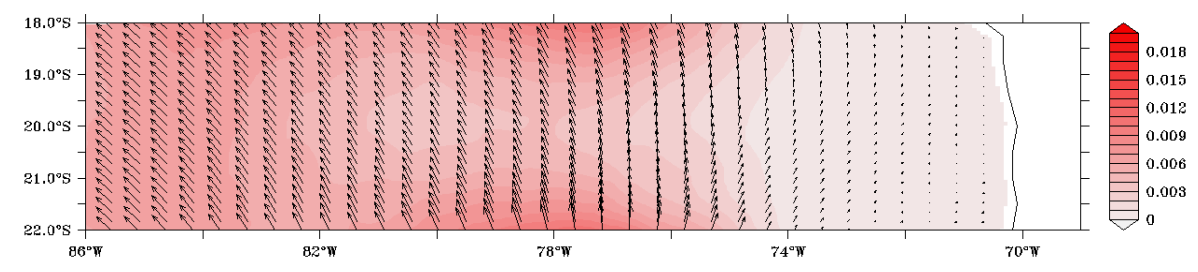

(a) Windstress (Non-assimilated)

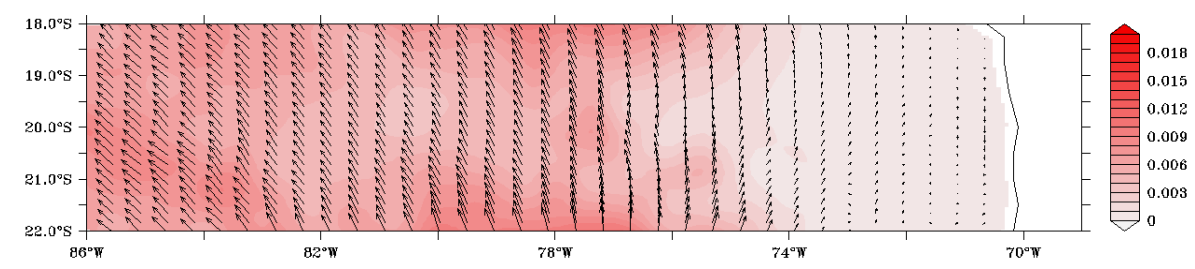

(b) Windstress (Assimilated)

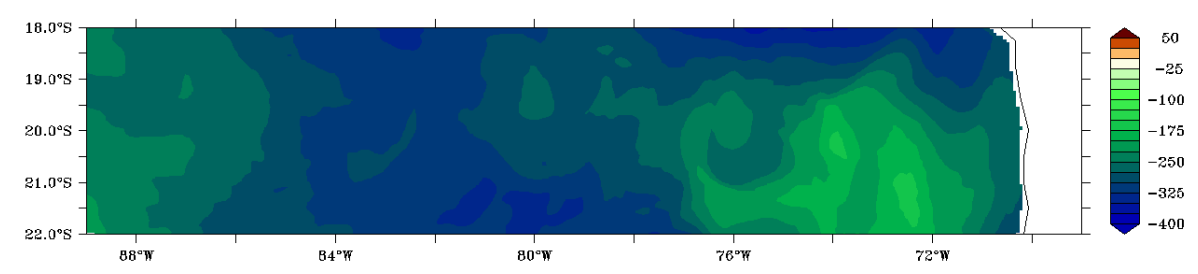

(c) Net Heat Flux (Non-assimilated)

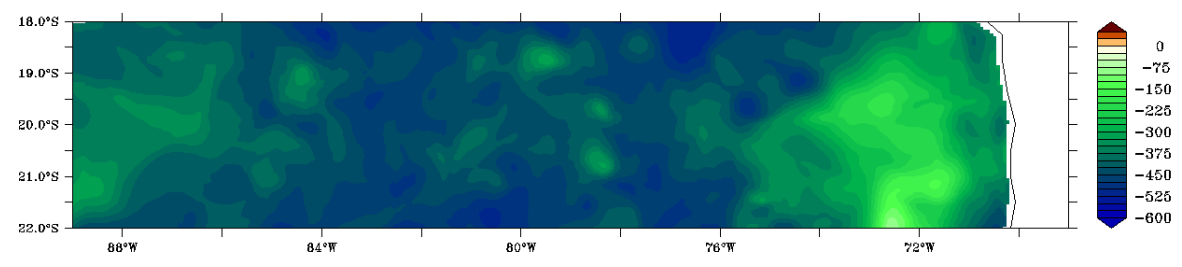

(d) Net Heat Flux (Assimilated)

Fig. 8. Windstress $\left(\mathrm{N} \mathrm{m}^{-2}\right)$ forcing for the ROMS model for the period from Nov 16-31 November 2008 before (a) and after (b) adjustment from assimilation of observations. Net Heat flux $\left(\mathrm{W} \mathrm{m}^{-2}\right)$ forcing for the ROMS model for the period from 16-31 November 2008 before (c) and after (d) adjustment from assimilation of observations.

the profiles. The eddy at $76^{\circ} \mathrm{W}$ and $19.5^{\circ} \mathrm{S}$ was mainly surveyed in the first fortnight but was also profile some more in the second fortnight.

The modifications to the forcing fields (both the windstress and the heat fluxes) at the surface due to assimilation for the two fortnights of November 2008 shown in Figs. 7 and 8 reveal changes on a broad scales with the overall pattern of the forcing remaining the same. The modifications show about a $10 \%$ reduced heating close to the coast and the heat fluxes in the rest of the domain remains about the same order of magnitude. The windstress magnitude does not change much but the direction changes by a few degrees in southeast part of the domain during first fortnight causing corresponding changes in the windstress curl. The model fits of SSH anomaly are shown in Fig. 9 compared with those estimated from AVISO. Both fits reveal similar large-scale patterns as the observations, with finer-scale structures in the model due to its higher resolution. The intensively surveyed eddy at $76^{\circ} \mathrm{W}$ and $19.5^{\circ} \mathrm{S}$ has a low SSH signature evident in both observations and model. The currents from the model plotted as vectors also reveal a cyclonic eddy at this location and much finer scale structures around it.

The model fits of SST along with satellite observations are shown in Fig. 10. Both fits reveal similar large-scale patterns similar to the observations, with considerable mesoscale structures that qualitatively resemble the observations. These mesoscale structures are not well constrained by the fit, likely due to the lack of adequate subsurface observations away from the cruise tracks, as well as nonlinearities in their evolution.

Subsurface variability is shown in Fig. 11, in which the $250 \mathrm{~m}$ temperature and velocity fields is shown for three times during November. The subsurface expression of the eddy at $\left(76^{\circ} \mathrm{W}, 19.5^{\circ} \mathrm{S}\right)$ is clearly captured by the fits. The 


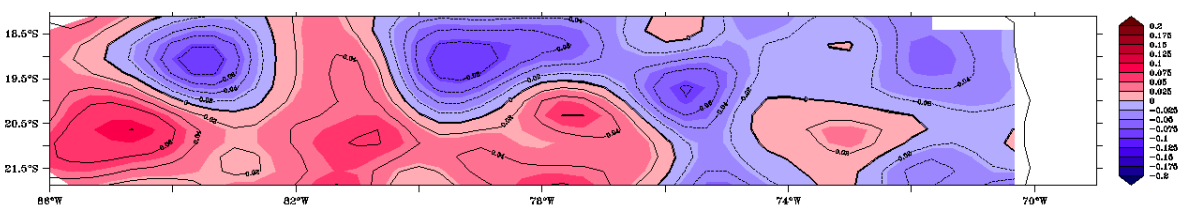

(a) Obs: 10 November

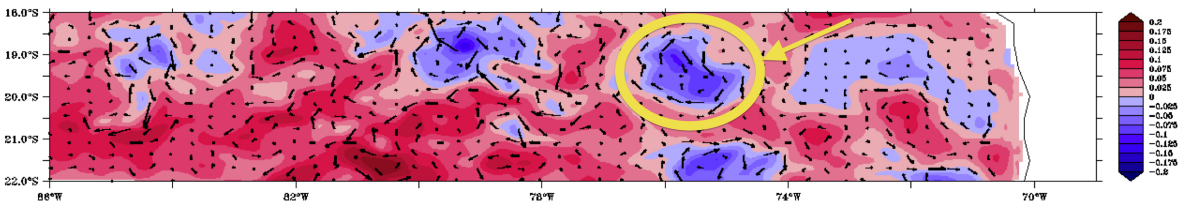

(b) ROMS: 10 November

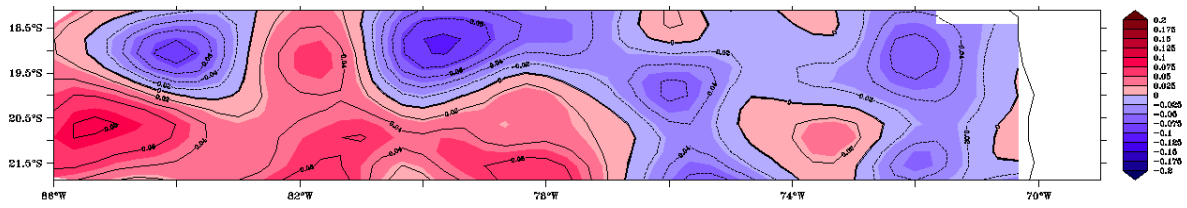

(c) Obs: 20 November

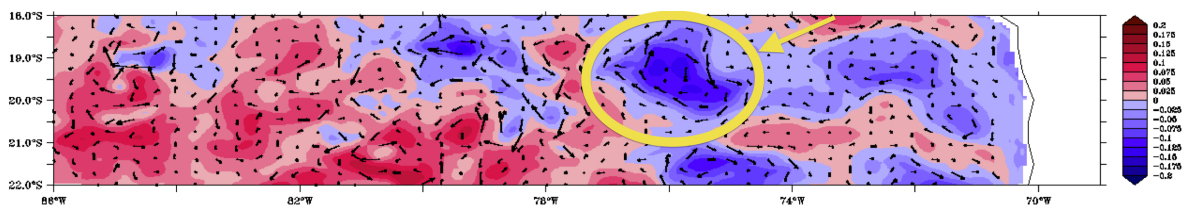

(d) ROMS: 20 November

Fig. 9. Sea level anomaly (in meters) from AVISO mapped fields in the (a) and (c) and from the ROMS ocean state estimate in (b) and (d). The velocities from the model are overlaid on the sea level anomaly contours to reveal cyclonic and anticyclonic eddies.

$250 \mathrm{~m}$ temperature shows the doming of the isotherms beneath the cyclonic eddy as found in previous studies of eddy structure in this region (Chaigneau et al., 2011). During the VOCALS campaign, it migrates slightly northwestward and elongates in the northwest-southeast orientation, possibly indicative of an eddy splitting event.

The strength of nonlinearities in this flow is tested with the Okubo-Weiss (OW) parameter (Weiss, 1991; Okubo, 1970) (Fig. 11d), which describes the relative dominance of strain and vorticity. Eddy identification procedures based on this parameter are prone to detrimental effects of noise in the computation (Chelton et al., 2011a). A threshold for OW must be set so as to distinguish coherent structures from the background field. Previous studies with satellite altimetry data have used $\mathrm{OW}=0.2 \sigma_{\mathrm{OW}}$, where $\sigma_{\mathrm{OW}}$ is the spatial standard deviation of OW. In an elliptic regime, rotation dominates deformation (and vice versa for hyperbolic). Eddy cores can therefore be identified as connected regions with negative values of OW. This criterion for eddy identification has been used successfully with data from sea level altimetry maps (Isern-Fontanet et al., 2003; Morrow et al., 2004). Closed contour structures with length scales greater than $10-20 \mathrm{~km}$ in Fig. $7 \mathrm{~d}$ are indicative of eddy-like structures (Chelton et al., 2007c). The OW highlights the eddy at $\left(76^{\circ} \mathrm{W}, 19.5^{\circ} \mathrm{S}\right)$ as well as the two cyclonic eddies at $80^{\circ} \mathrm{W}$ and $84^{\circ} \mathrm{W}$.

Figure 12 shows eddy kinetic energy averaged for a week during the cruise period when the subsurface eddy at $\left(76^{\circ} \mathrm{W}\right.$, $19.5^{\circ} \mathrm{S}$ ) was intensively surveyed. The top panel (Fig. 12a) shows the overlaying SLA contours from satellite altimetry and the second panel (Fig. 12b) shows the contours of model SLA overlaid on EKE. This further reveals the intensity of the eddies (cyclonic and anticyclonic) showing that the observed eddy was of moderate intensity compared to the other eddies that occurred during this time period. The bottom two panels (Fig. 12c and d) show the evolution of the EKE over a period of a week during the cruise period revealing persistent eddy structures which morph into different shapes preserving their EKE as they propagate.

The vertical structure of the eddy field is shown in a depthlongitude cross-section in Fig. 13. The deep structure of the eddy at $76^{\circ} \mathrm{W}$ is evident by the doming isopycnals extending from 50 to $400 \mathrm{~m}$ depth. The subsurface velocities associated with this are stronger near the surface, reaching $40 \mathrm{~cm} \mathrm{~s}^{-1}$, 


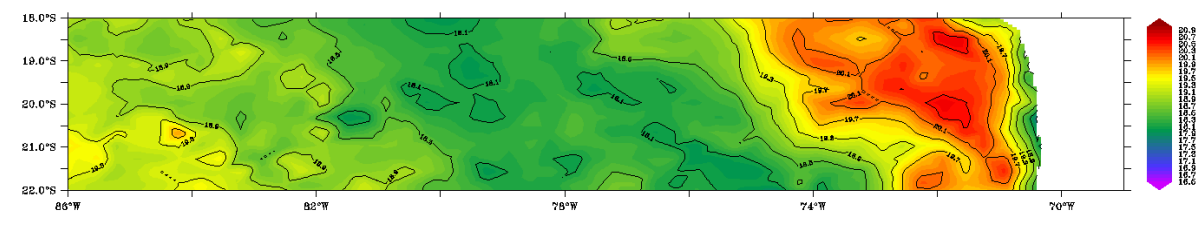

(a) Obs: 10 November

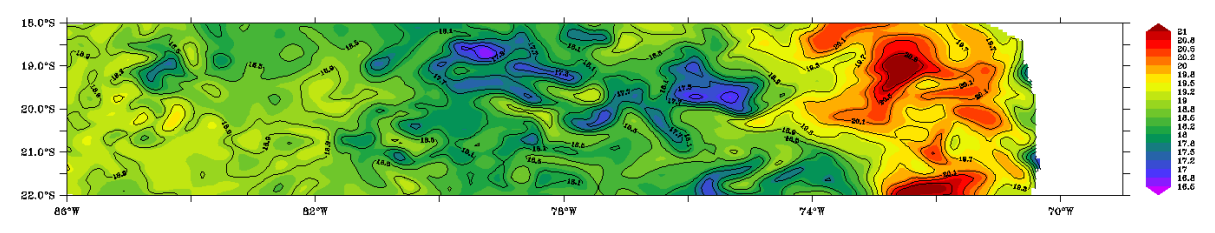

(b) ROMS:10 November

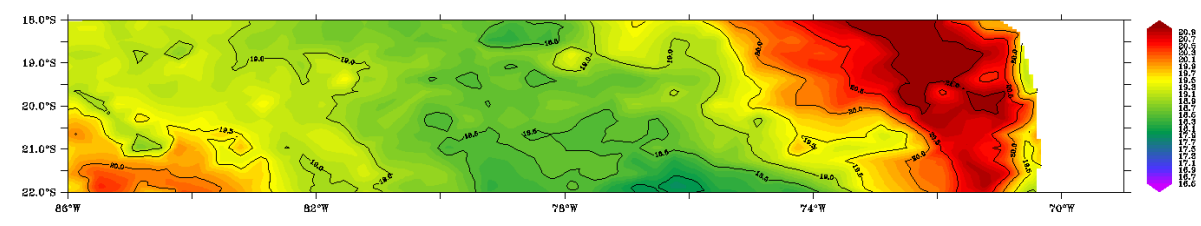

(c) Obs: 20 November

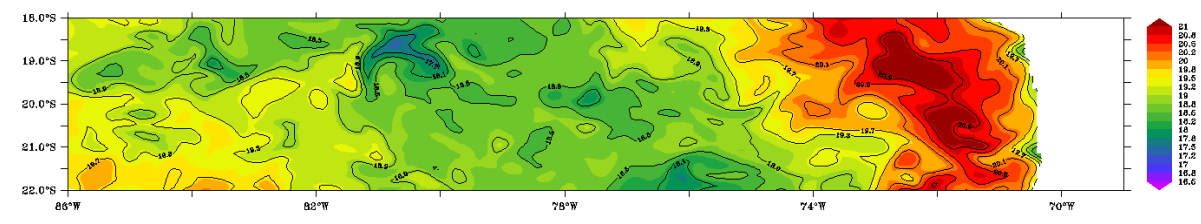

(d) ROMS: 20 November

Fig. 10. SST (in ${ }^{\circ} \mathrm{C}$ ) from NOAA Optimally Interpolated observations in (a) and (c) and SST from ROMS with the model velocities overlaid for the days 10 and 20 November 2008.

and weaker at depth, typically $10-20 \mathrm{~cm} \mathrm{~s}^{-1}$. The core of the eddy has a salinity minimum, as shown in Fig. 14, where the velocity field has its zero crossing, which indicates its circulation strength and its isolation from the surrounding waters. This is consistent with the similar cyclonic eddies with salinity minima studied previously by Chaigneau et al. (2011). They show the core of cyclonic eddies in this region are located at about $150 \mathrm{~m}$ depth within the thermocline. They also show that the anticyclonic eddies are centered below the thermocline at $400 \mathrm{~m}$ depth. This difference was attributed to the mechanisms involved in the eddy formation. While intrathermocline CEs would be formed by instabilities of the surface equatorward coastal currents, the subthermocline AEs are likely to be shed by the subsurface poleward Peru-Chile Undercurrent. These salinity lenses which have been related to the Eastern South Pacific Intermediate Water in previous studies (Schneider et al., 2003), seem to be relatively isolated and poorly mixed with surrounding waters especially near the Nazca ridge, a topographic feature which stretches diagonally across the domain (Fig. 2). This ridge is also a region of high nonlinear eddy activity as evidenced in the Fig. 11d of higher number of closed contours of OW parameter in this region during this period.

\section{Upper ocean heat budget}

In this section, a regional heat balance is constructed for the upper ocean of the high resolution ocean state estimate for a two week period. The time-mean oceanic heat balance integrated over the upper ocean is

$$
\begin{gathered}
\int_{z_{0}}^{\eta} \rho_{0} C_{p} \partial_{t} \bar{T} \mathrm{~d} z=-\int_{z_{0}}^{\eta} \rho_{0} C_{p} \nabla \cdot \overline{\boldsymbol{u} T} \mathrm{~d} z+Q_{\text {net }} \\
-\left.\rho_{0} C_{p} \overline{\kappa_{\mathrm{v}} \partial_{z} T}\right|_{z_{0}}-\int_{z_{0}}^{\eta} \rho_{0} C_{p} \kappa_{\mathrm{h}} \nabla^{2} T,
\end{gathered}
$$

where $Q_{\text {net }}$ is the net surface heat flux, $C_{p}$ is the specific heat of seawater at constant pressure, $\rho_{0}$ is the density of seawater, $\boldsymbol{u}$ is the total velocity vector, $T$ is temperature and $\kappa_{\mathrm{V}}$ and $\kappa_{\mathrm{h}}$ are the subgrid-scale horizontal and vertical eddy diffusivity parameters. The first term on the left hand side is 


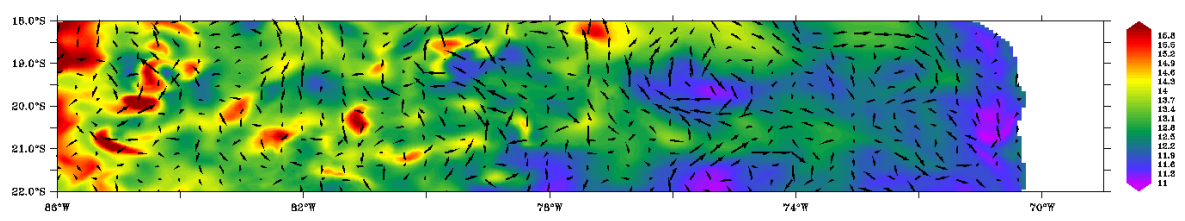

(a) ROMS:10 November

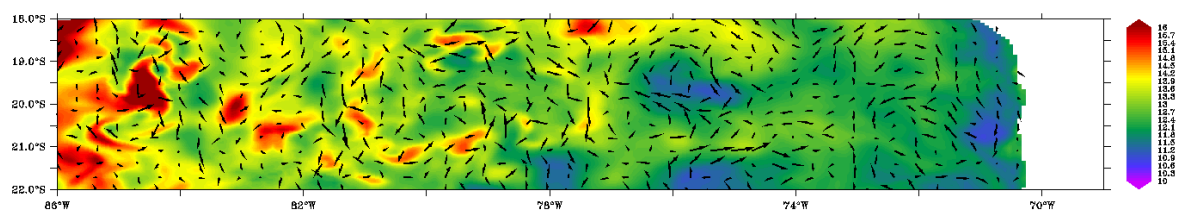

(b) ROMS:14 November

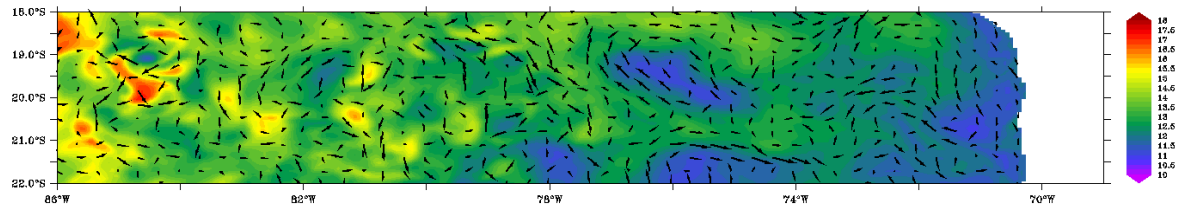

(c) ROMS:18 November

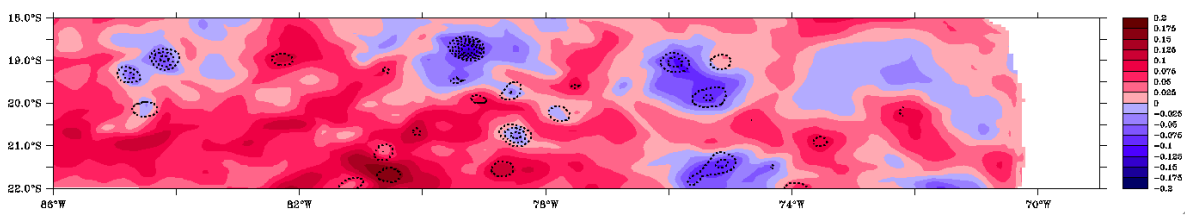

(d) ROMS SSH:10 November

Fig. 11. Temperature (in ${ }^{\circ} \mathrm{C}$ ) at $250 \mathrm{~m}$ Depth in the ocean state estimate for three different days (a) 10 November, (b) 14 November and (c) 20 November showing the evolution of the eddy in time in the model. The last (d) is the color contours of SLA with the Okubo-Weiss parameter overlaid on top to show eddy like structures.

the rate of temperature change (or temperature tendency), the first term on the right-hand side is the temperature advection followed by the terms for net surface heat flux and horizontal and vertical diffusion, respectively. These terms are saved and averaged over the duration of the ROMS simulation.

Although a long-term balance of the heat equation can not be computed with this short data assimilation fit, the ocean state estimate can still be analyzed to understand the key mechanisms which are in balance during the period of the cruise. The solution is integrated from 0 to $400 \mathrm{~m}$ depth, below which vertical advection is small, based on inspecting plots of this field. Hence, the vertically integrated advection term in the heat balance equation is dominantly the horizontal advection term.

The spatial pattern of each term of Eq. (3) in the model heat balance for the period during which the eddy was observed intensively is shown in Fig. 15. The advection (Fig. 15b) and vertical diffusion (Fig. 15c) terms are the dominant terms, with magnitudes similar to that of the temperature tendency for this short-term two-week-averaged balance. The horizontal diffusion term (Fig. 15d) has a smaller magnitude and has much smaller spatial scale structures than the other terms, and will be ignored in subsequent discussion.

The pattern of the mean sea level anomaly during the period is plotted as line contours over the tendency (color) contours in Fig. 15a. The cyclonic eddy at $76^{\circ} \mathrm{W}$ exhibits a dipolar pattern in the heat budget with advection by cooling on the western side and vice versa to the east. The pattern is nearly symmetric, with cooling and warming, averaging nearly to zero over the spatial pattern of the eddy indicated by the box in Fig. 15b. Likewise, box averages over larger areas of the the cruise region yield very small imbalances for the advection term. The vertical diffusion term, in contrast, (Fig. 15c) has a net cooling effect over the entire domain. This term includes the net warming at the surface as well as the cooling by vertical mixing throughout the water column. Clearly the vertical mixing processes contribute significantly to cooling broad-scale averages of the upper ocean in this region and dominates over the lateral advection effects of the smallerscale eddies during the short period of the cruise. The cumulative long-term impact of these eddies on the heat budget cannot be identified in these short data assimilation fits. Since the heat balance computation in the state estimate of the region is 


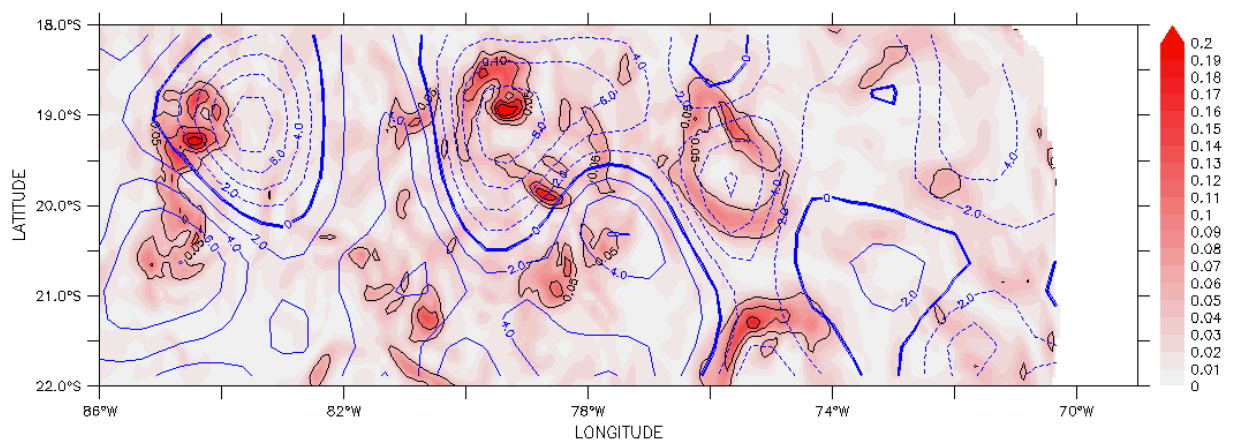

(a) ROMS EKE averaged for 1-15 November with Observed SLA line contours overlaid for 11 November

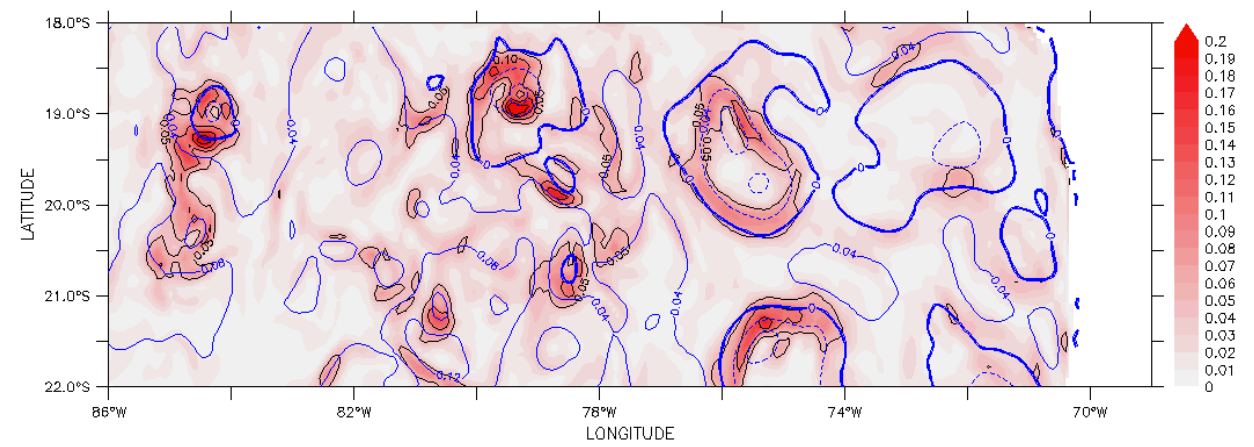

(b) ROMS EKE averaged for 1-15 November with ROMS SLA line contours overlaid for 11 November

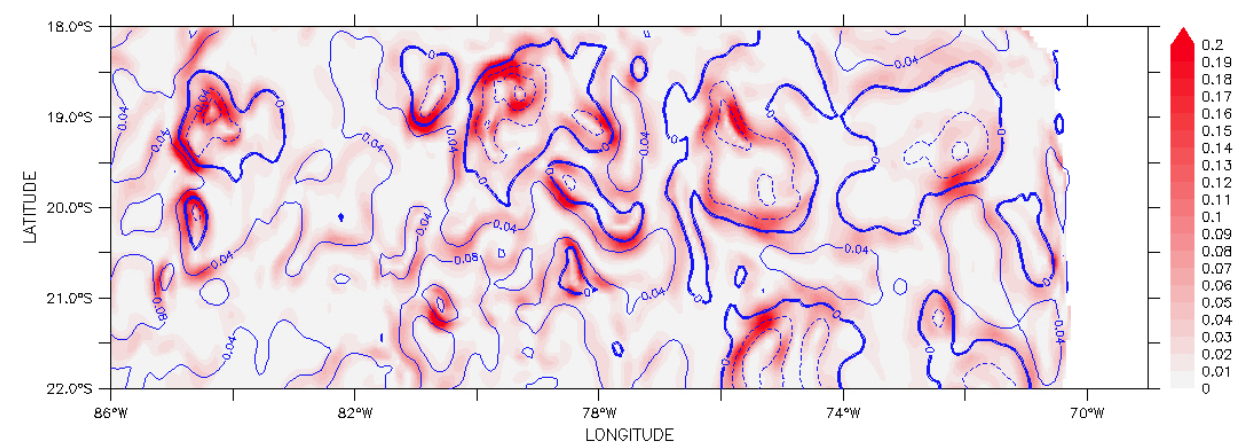

(c) EKE with ROMS SLA Contours for 9 November

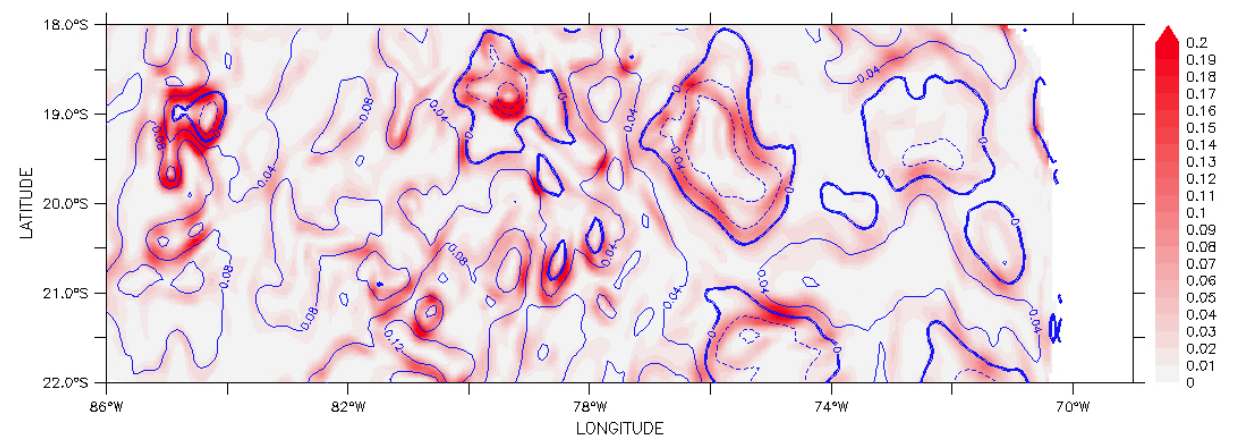

(d) EKE with ROMS SLA Contours for 15 November

Fig. 12. Eddy Kinetic Energy (EKE) averaged for the first two weeks of November from the model overlaid on the (a) AVISO SLA and (b) ROMS SLA. EKE are daily averaged for (c) 9 November and (d) 15 November. 


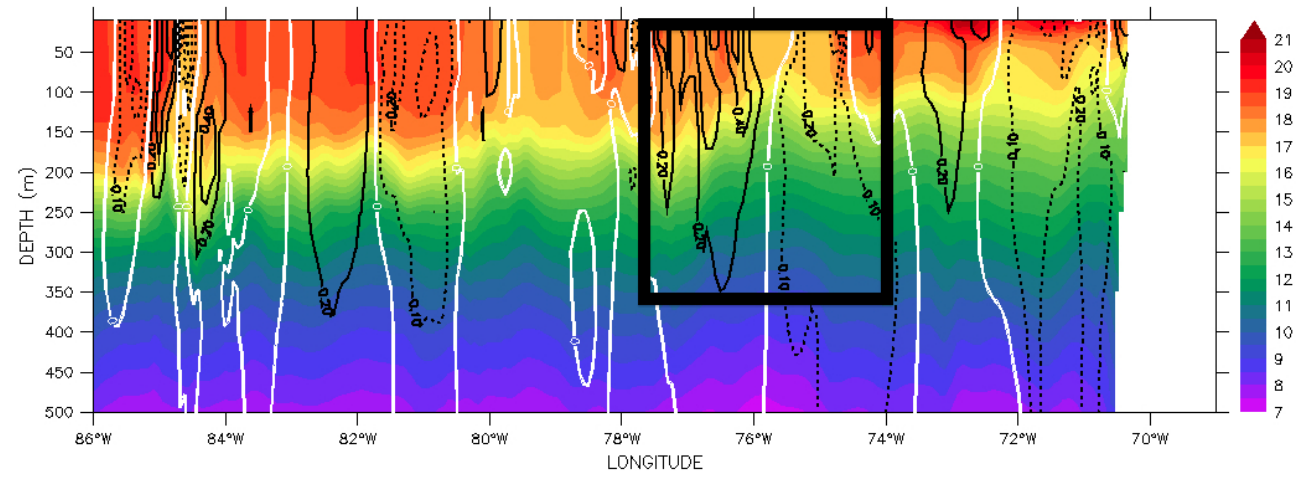

Fig. 13. Vertical temperature (in ${ }^{\circ} \mathrm{C}$ ) profiles (color) and meridional velocity $\left(\mathrm{m} \mathrm{s}^{-1}\right.$, line contours) with positive values (continuous lines) and negative values (dashed lines) for 10 November revealing the eddy structure in depth. The profile is plotted at $20^{\circ} \mathrm{S}$ from 86 to $69^{\circ} \mathrm{W}$.

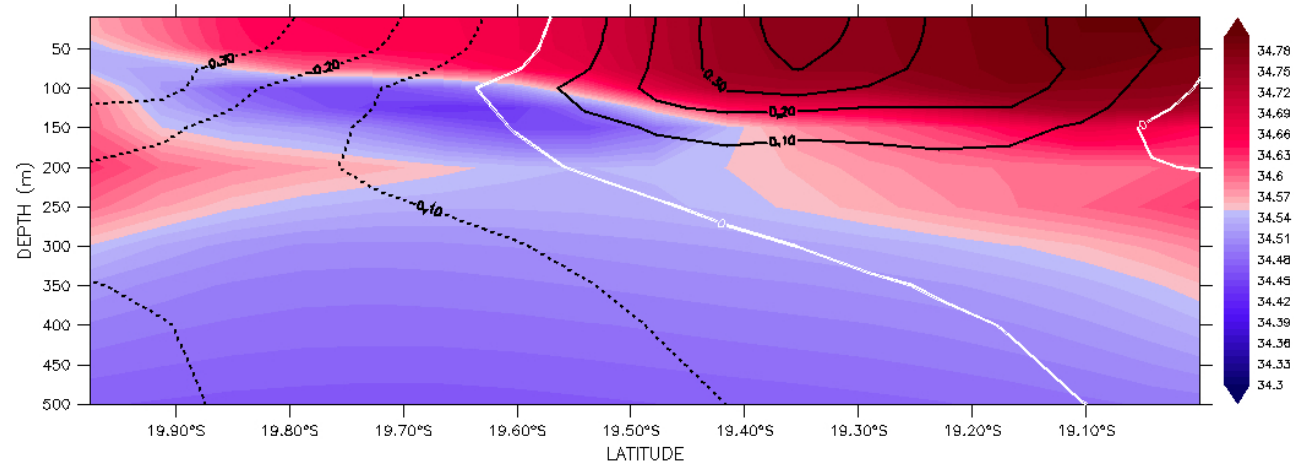

Fig. 14. Zonal velocities $\left(\mathrm{m} \mathrm{s}^{-1}\right)$ of eddy at $76^{\circ} \mathrm{W}$ on the same day 10 November with the color contours showing salinity (psu). The positive velocities are shown as continuous lines and the negative values as dashed line contours. The cross-section is from 20 to $19^{\circ} \mathrm{S}$.

for a short period of time (November 2008) during the cruise, an insight into the impact of eddies on long-term cross-shore heat and salt transport in this region is beyond the scope of this study.

\section{Summary and discussion}

This study examines the upper-ocean variability observed during the VOCALS-REx cruise of 2008 by using ocean state estimation with ROMS. Nonlinearities in the system prevent a 30-day fit, so two 15-day fits are executed for the available observations of hydrographic temperature and salinity and satellite fields of SST and sea-level height. The fits reduce the cost function significantly and ROMS is able to successfully reproduce both large-scale and smaller-scale features of the flows observed during the cruises.

Particular attention is focused on an intensively studied eddy at $76^{\circ} \mathrm{W}, 19^{\circ} \mathrm{S}$. The ROMS fits capture this eddy as an isolated rotating vortex with a strong subsurface signature in velocity, temperature and anomalous low salinity. The eddy has an average temperature anomaly of approximately $-0.5^{\circ} \mathrm{C}$ over a depth range from $50-600 \mathrm{~m}$ and features a cold anomaly of approximately $-1{ }^{\circ} \mathrm{C}$ near $150 \mathrm{~m}$ depth. The eddy moves northwestward and elongates during the second 15-day fit. It exhibits a strong signature in the OW parameters, which indicates significant nonlinearity in its evolution.

The heat balance for the period of the cruise from the ocean state estimate reveals that the horizontal advection and the vertical mixing processes are the dominant terms that balance the temperature tendency of the upper layer of the ocean locally in time and space. Areal averages during this period, however, around the eddies or around the cruise tracks suggest that vertical mixing processes generally balance the surface heating. There is a lack of consensus regarding the importance of eddy heat flux divergence in balancing the climatological upper ocean heat budget for this region in studies over the past decade (Colbo and Weller, 2007; Toniazzo et al., 2009; Zheng et al., 2010; Chaigneau et al., 2011). The results presented here are only a quasi-instantaneous heat budget analysis and cannot be extended to interpret the longterm impact of eddies on the cross-shore transport of heat or salt. Long term observational, modeling and assimilation studies need to be performed to understand the role of eddies in balancing the climatological upper ocean heat balance in this region. 


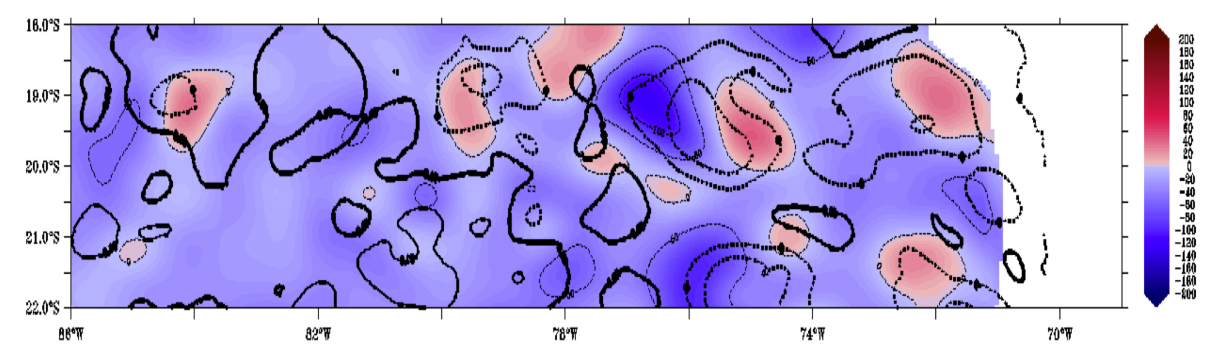

(a) Temperature Tendency

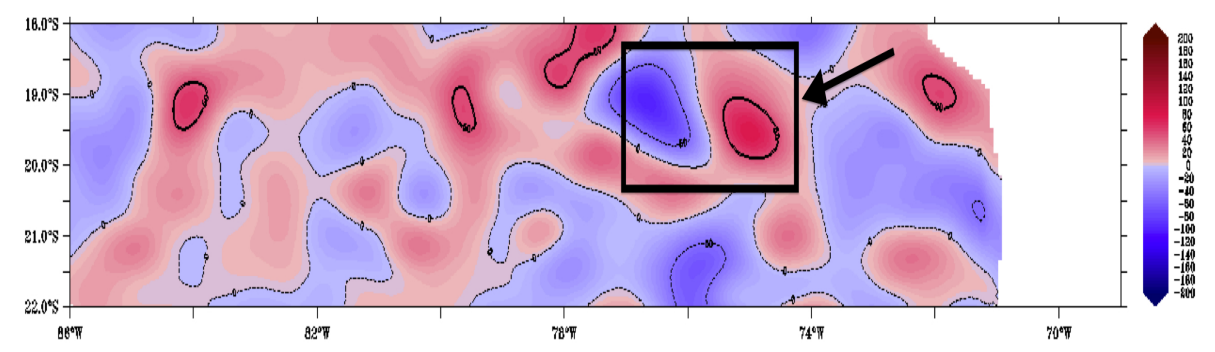

(b) Advection with SLA contours overlaid

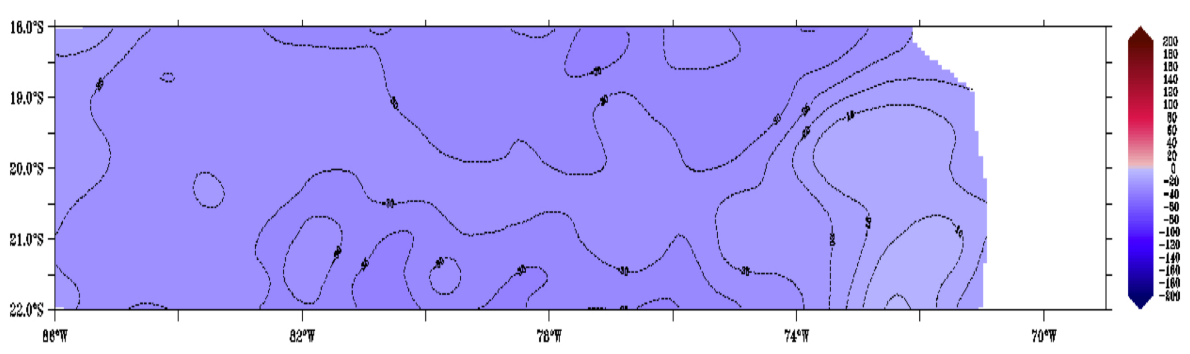

(c) Vertical Diffusion

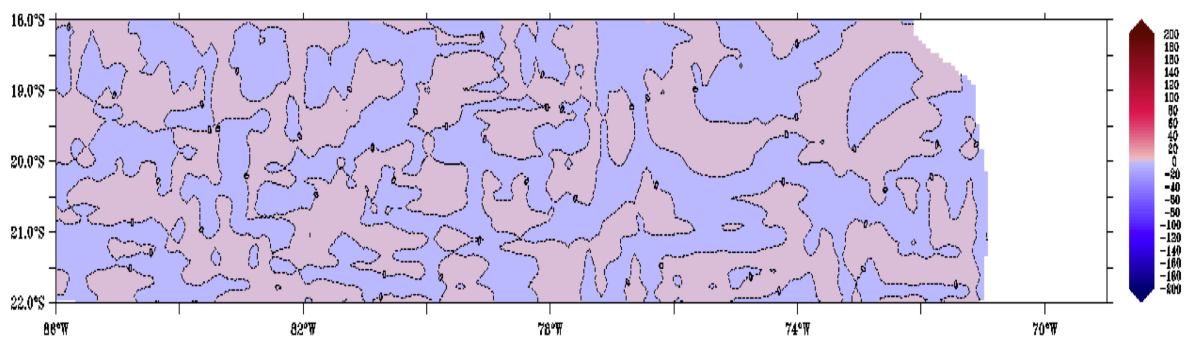

(d) Horizontal Diffusion

Fig. 15. Spatial maps of heat budget $\left(\mathrm{W} \mathrm{m}^{-2}\right)$ terms from the model for $86-69^{\circ} \mathrm{W}$ and $22-18^{\circ} \mathrm{S}$. The heat budget terms are integrated to the depth of $400 \mathrm{~m}$ and for a period of two weeks when the eddy was strongest. The eddy region is highlighted by a black box around in (b) and by the SLA contour overlaid in (a).

The results in this study may also be of interest to the biogeochemical community to investigate links between ecosystems, biogenic oceanic aerosols and mesoscale eddies in the highly productive Peru-Chile Current System. Further work is needed to understand how the upper-ocean processes couple to the atmospheric processes and the role of the oceanic aerosols and its complex relationship with the stratus deck in modulating and maintaining the temperate climate in this region.

Acknowledgement. This research forms a part of the Ph.D. dissertation of AS. This work was supported by National Science Foundation funding (OCE-0744245) VOCALS: Mesoscale Ocean Dynamical Analysis with Synoptic Data Assimilation and Coupled Ocean-Atmosphere Modeling and (OCE10-26607) for the 
California Current Ecosystem Long Term Ecological Research site. RAW and FS were supported by NOAA (NA09OAR4320129). We thank the scientific party and the crew of the NOAA ship Ronald $\mathrm{H}$. Brown who helped in collecting the hydrographic data during VOCALS-REx. The altimeter products were produced by SSALTO-DUACS and distributed by AVISO with support from CNES. The AVHRR-Pathfinder SST data were obtained from the Physical Oceanography Distributed Active Archive Center (PO.DAAC) at the NASA Jet Propulsion Laboratory. AS would like to thank Dian Putrasahan, Jamie Holte, Vincent Combes for many discussions regarding the ocean-atmosphere dynamics in this region.

Edited by: C. R. Mechoso

\section{References}

Albert, A., Echevin, V., Lévy, M., and Aumont, O.: Impact of nearshore wind stress curl on coastal circulation and primary productivity in the Peru upwelling system, J. Geophys. Res., 115, C12033, doi:10.1029/2010JC006569, 2010.

Amador, J., Alfaro, E., Lizano, O., and Magaña, V.: Atmospheric forcing of the eastern tropical Pacific: A review, Prog. Oceanogr., 69, 101-142, doi:10.1016/j.pocean.2006.03.007, 2006.

Capet, X., Colas, F., Penven, P., Marchesiello, P., and McWilliams, J.: Eddies in eastern boundary subtropical upwelling systems, Ocean modeling in an Eddying regime, Geophys. Monogr. Ser., AGU, Washington DC, 177, 131-147, doi:10.1029/177GM10, 2008.

Chaigneau, A., Le Texier, M., Eldin, G., Grados, C., and Pizarro, Ó.: Vertical structure of mesoscale eddies in the eastern South Pacific Ocean: A composite analysis from altimetry and Argo profiling floats, J. Geophys. Res., 116, C11025, doi:10.1029/2011JC007134, 2011.

Chelton, D. B., Schlax, M. G., and Samelson, R. M.: Global observations of nonlinear mesoscale eddies, Prog. Oceanogr., 91, 167-216, 2011a.

Chelton, D. B., Gaube, P., Schlax, M. G., Early, J. J., and Samelson, R. M.: The Influence of Nonlinear Mesoscale Eddies on Near-Surface Oceanic Chlorophyll, Science, 334, 328-332, doi:10.1126/science.1208897, 2011b.

Chelton, D. B., Schlax, M., Samelson, R. M., and de Szoeke, R.: Global observations of large oceanic eddies, Geophys. Res. Lett., 34, L15606, doi:10.1029/2007GL030812, 2007c.

Clarke, A. D., Davis, D., Kapustin, V. N., Eisele, F., Chen, G., Paluch, I., Lenschow, D., Bandy, A. R., Thornton, D., Moore, K., Mauldin, L., Tanner, D., Litchy, M., Carroll, M. A., Collins, J., and Albercook, G.: Particle nucleation in the tropical boundary layer and its coupling to marine sulfur sources, Science, 282, 89-92, 1998.

Colas, F., Mcwilliams, J. C., Capet, X., and Kurian, J.: Heat balance and eddies in the Peru-Chile current system, Clim. Dynam., 39, 509-529, doi:10.1007/s00382-011-1170-6, 2011.

Colbo, K. and Weller, R.: The variability and heat budget of the upper ocean under the Chile-Peru stratus, J. Mar. Res., 65, 607637, 2007.

de Szoeke, S., Fairall, C., Wolfe, D., Bariteau, L., and Zuidema, P.: Surface flux observations on the southeastern tropical Pacific Ocean and attribution of SST errors in cou- pled ocean-atmosphere models, J. Climate, 23, 4152-4174, doi:10.1175/2010JCLI3411.1, 2010.

Di Lorenzo, E., Moore, A. M., Arango, H. G., Cornuelle, B. D., Miller, A. J., Powell, B., Chua, B. S., and Bennett, A. F.: Weak and strong constraint data assimilation in the inverse Regional Ocean Modeling System (ROMS): Development and application for a baroclinic coastal upwelling system, Ocean Model., 16, 160-187, 2007.

Echevin, V., Puillat, I., Grados, C., and Dewitte, B.: Seasonal and mesoscale variability in the Peru upwelling system from in situ data during the years 2000 to 2004, Gayana (Concepción), 68, 167-173, 2004.

Fairall, C. W., Bradley, E., Hare, J., Grachev, A., and Edson, J.: Bulk parameterization of air-sea fluxes: Updates and verification for the COARE algorithm, J. Climate, 16, 571-591, doi:10.1175/1520-0442(2003)016<0571:BPOASF >2.0.CO;2, 2003.

Garreaud, R. and R. Muñoz: The low-level jet off the west coast of subtropical South America: Structure and variability, Mon. Weather Rev., 133, 2246-2261, doi:10.1175/MWR3074.1, 2005.

Haidvogel, D. B., Arango, H. G., Budgell, W. P., Cornuelle, B. D., Curchitser, E., Di Lorenzo, E., Fennel, K., Geyer, W. R., Hermann, A. J., and Lanerolle, L.: Ocean forecasting in terrainfollowing coordinates: Formulation and skill assessment of the Regional Ocean Modeling System, J. Comput. Phys., 227, 35953624, doi:10.1016/j.jcp.2007.06.016, 2008.

Hind, A. J., Rauschenberg, C. D., Johnson, J. E., Yang, M., and Matrai, P. A.: The use of algorithms to predict surface seawater dimethyl sulphide concentrations in the SE Pacific, a region of steep gradients in primary productivity, biomass and mixed layer depth, Biogeosciences, 8, 1-16, doi:10.5194/bg-8-1-2011, 2011.

Isern-Fontanet, J., García-Ladona, E., and Font, J.: Identification of marine eddies from altimetric maps, J. Atmos. Ocean. Tech., 20, 772-778, doi:10.1175/15200426(2003)20<772:IOMEFA > 2.0.CO;2, 2003.

Kalnay, E., Kanamitsu, M., Kistler, R., Collins, W., Deaven, D., Gandin, L., Iredell, M., Saha, S., White, G., Woollen, J., Zhu, Y., Leetmaa, A., Reynolds, R., Zhu, Y., Leetmaa, A., Reynolds, R., Chelliah, M., Ebisuzaki, W., Higgins, W., Janowiak, J., Mo, K. C., Ropelewski, C., Wang, J., Jenne, R., and Joseph, D.: The NCEP/NCAR 40-year reanalysis project, B. Am. Meteorol. Soc., 77, 437-471, 1996.

Klein, S. and Hartmann, D.: The seasonal cycle of low stratiform clouds, J. Climate, 6, 1587-1606, doi:10.1175/15200442(1993)006<1587:TSCOLS > 2.0.CO;2, 1993.

Large, W. G. and Danabasoglu, G.: Attribution and Impacts of Upper-Ocean Biases in CCSM3, J. Climate, 19, 2325-2346, doi:10.1175/JCLI3740.1, 2006.

Large, W. G., Mcwilliams, J. C., and Doney, S. C.: Oceanic vertical mixing: A review and a model with a nonlocal boundary layer parameterization, Rev. Geophys., 32, 363-403, 1994.

Ma, C. C., Mechoso, C. R., Robertson, A. W., and Arakawa, A.: Peruvian stratus clouds and the tropical Pacific circulation: A coupled ocean-atmosphere GCM study, J. Climate, 9, 1635-1645, 1996.

Masumoto, Y., Sasaki, H., Kagimoto, T., Komori, N., Ishida, A., Sasai, Y., Miyama, T., Motoi, T., Mitsudera, H., Takahashi, K., Sakuma, H., and Yamagata, T.: A fifty-year eddy-resolving simulation of the world ocean: Preliminary outcomes of OFES 
(OGCM for the Earth Simulator), J. Earth Simulator, 1, 35-56, 2004.

Mechoso, C. R., Robertson, A. W., Barth, N., Davey, M. K., Delecluse, P., Gent, P. R., Ineson, S., Kirtman, B., Latif, M., Le Treut, H., Nagai, T., Neelin, J. D., Philander, S. G. H., Polcher, J., Stockdale, T., Terray, L., Thual, O., and Tribbia, J. J.: The seasonal cycle over the tropical Pacific in coupled ocean-atmosphere general circulation models, Mon. Weather Rev., 123, 2825-2838, 1995.

Moore, A. M., Arango, H. G., Broquet, G., Powell, B. S., ZavalaGaray, J., and Weaver, A.: The Regional Ocean Modeling System (ROMS) 4-Dimensional Variational Data Assimilation Systems: I-System overview and formulation, Prog. Oceanogr., 91, 34-49, doi:10.1016/j.pocean.2011.05.004, 2010.

Moore, A. M., Arango, H. G., Broquet, G., Edward, C., Veneziani, M., Powell, B., Foley, D., Doyle, J. D., Costa, D., and Robinson, P.: The Regional Ocean Modeling System (ROMS) 4dimensional variational data assimilation systems. Part II: Performance and Application to the California Current System, Prog. Oceanogr., 91, 50-73, doi:10.1016/j.pocean.2011.05.003, 2011.

Morrow, R., Birol, F., Griffin, D., and Sudre, J.: Divergent pathways of cyclonic and anti-cyclonic ocean eddies, Geophys. Res. Lett., 31, L24311, doi:10.1029/2004GL020974, 2004.

Okubo, A.: Horizontal dispersion of floatable particles in the vicinity of velocity singularities such as convergences, Deep-Sea Res., 17, 445-454, doi:10.1016/0011-7471(70)90059-8, 1970.

Penven, P., Echevin, V., Pasapera, J., Colas, F., and Tam, J.: Average Circulation, Seasonal Cycle, and Mesoscale Dynamics of the Peru Current System: a Modeling Approach, J. Geophys. Res., 110, C10021, doi:10.1029/2005JC002945, 2005.

Schneider, W., Fuenzalida, R., Rodríguez-Rubio, E., Garcés-Vargas, J., and Bravo, L.: Characteristics and formation of Eastern South Pacific Intermediate Water, Geophys. Res. Lett., 30, 1581, doi:10.1029/2003GL017086, 2003.

Shchepetkin, A. and McWilliams, J.: The regional oceanic modeling system (ROMS): a split-explicit, free-surface, topographyfollowing-coordinate oceanic model, Ocean Model., 9, 347-404, doi:10.1016/j.ocemod.2004.08.002, 2005.

Strub, P. T., Mesías, J. M., Montecino, V., Rutllant, J., and Salinas, S.: Coastal ocean circulation off western South America. Coastal segment (6, E), The Sea, 11, 273-313, 1998.

Taylor, K.: Summarizing multiple aspects of model performance in a single diagram, J. Geophys. Res., 106, 7183-7192, doi:10.1029/2000JD900719, 2001.

Toniazzo, T., Mechoso, C. R., Shaffrey, L. C., and Slingo, J. M.: Upper-ocean heat budget and ocean eddy transport in the southeast Pacific in a high-resolution coupled model, Clim. Dynam., 35, 1309-1329, doi:10.1007/s00382-009-0703-8, 2009.
Weiss, J.: The dynamics of enstrophy transfer in two-dimensional hydrodynamics, Physica D, 48, 273-294, doi:10.1016/01672789(91)90088-Q, 1991.

Wood, R., Mechoso, C. R., Bretherton, C. S., Weller, R. A., Huebert, B., Straneo, F., Albrecht, B. A., Coe, H., Allen, G., Vaughan, G., Daum, P., Fairall, C., Chand, D., Gallardo Klenner, L., Garreaud, R., Grados, C., Covert, D. S., Bates, T. S., Krejci, R., Russell, L. M., de Szoeke, S., Brewer, A., Yuter, S. E., Springston, S. R., Chaigneau, A., Toniazzo, T., Minnis, P., Palikonda, R., Abel, S. J., Brown, W. O. J., Williams, S., Fochesatto, J., Brioude, J., and Bower, K. N.: The VAMOS Ocean-Cloud-AtmosphereLand Study Regional Experiment (VOCALS-REx): goals, platforms, and field operations, Atmos. Chem. Phys., 11, 627-654, doi:10.5194/acp-11-627-2011, 2011.

Xie, S.-P.: The shape of continents, air-sea interaction, and the rising branch of the Hadley circulation, Adv. Global Change Res., 21, 121-152, doi:10.1007/978-1-4020-2944-8_4, 2004.

Yang, M., Blomquist, B. W., and Huebert, B. J.: Constraining the concentration of the hydroxyl radical in a stratocumulus-topped marine boundary layer from sea-to-air eddy covariance flux measurements of dimethylsulfide, Atmos. Chem. Phys., 9, 92259236, doi:10.5194/acp-9-9225-2009, 2009.

Yang, M., Huebert, B. J., Blomquist, B. W., Howell, S. G., Shank, L. M., McNaughton, C. S., Clarke, A. D., Hawkins, L. N., Russell, L. M., Covert, D. S., Coffman, D. J., Bates, T. S., Quinn, P. K., Zagorac, N., Bandy, A. R., de Szoeke, S. P., Zuidema, P. D., Tucker, S. C., Brewer, W. A., Benedict, K. B., and Collett, J. L.: Atmospheric sulfur cycling in the southeastern Pacific longitudinal distribution, vertical profile, and diel variability observed during VOCALS-REx, Atmos. Chem. Phys., 11, 50795097, doi:10.5194/acp-11-5079-2011, 2011.

Zheng, X., Albrecht, B., Jonsson, H. H., Khelif, D., Feingold, G., Minnis, P., Ayers, K., Chuang, P., Donaher, S., Rossiter, D., Ghate, V., Ruiz-Plancarte, J., and Sun-Mack, S.: Observations of the boundary layer, cloud, and aerosol variability in the southeast Pacific near-coastal marine stratocumulus during VOCALSREx, Atmos. Chem. Phys., 11, 9943-9959, doi:10.5194/acp-119943-2011, 2011.

Zheng, Y., Shinoda, T., Kiladis, G., Lin, J., and Metzger, E.: Upper Ocean Processes Under the Stratus Cloud Deck in the Southeast Pacific Ocean, J. Phys. Oceanogr., 40, 103-120, doi:10.1175/2009JPO4213.1, 2010. 